13. Povishenye effectivnosti I bezopasnosti burovzrivnyh rabot / I.M. Murzikov,Es. Gorev, V.I/ Lantev,A.N.Zamotaev// Tsetnaya metallurgiya/-1990. № $5 .=$ C. $1-5$.

14. Turchaninov I.A., Iosiv M.A., Kasparyan E.V. Osnovi mechaniki gornyh porod.L.:Nedra,1977.-503s.

15. Mashanov A.A Treshinovatost gornyh porod.Almaty, 2000.-124c.

16. Mostkov V.M. Podzemnye sooruzhenya bolshogo sechenya.M.:Nedra,1974.-320s.

17. Erofeev I.E. povizenye effectivnosti burovzrivnih rabot na rudnikah.M.:Nedra,1988.-271s.

18. Sovershenstvovanye metodov podzemnoy razrabotki Ziryanovskogo mestorozhdenya. Collectiv avtorov. Alma-Ata: Kazakhstan,1975.-384s.

19. Spravochnik. Otkrytie gornyh raboti. M.;Gornoe byuro, 1994.-512s.

20 Airapetyan L.G., Bogolubov A.A. Analiz issledovanya uchastkovih drobilnih kompleksov na podzemnih rudnika// Tsvetnaya metallurgiya.-1990, №.-S.8587.

21. Bronikov D.M., Vanesov N.F., Bogdanov G.I. Razrabotka rud na bolshih glubinah . M.; Nedra, 1982.-292s.

22. Rikovskyi B.B., Batuev M.A., Hudov S.V., Dubskih A.V Burimost I vzrivaemost piroksenitov Gusevogorskogo mestorozhdenya// Gornyi jurnal/-1991, №S.59-60

23. Mashukov V.I. Deistvie vzriva na okruzhayushuyu sredu I sposoby upravlenya im. M.;Nedra,1976.-248s.

24. Stazhevskyi S.B., Phreidin A.M. Rusin E.P. Na podzemnih rudnikah Swetci ( Sostoyanye I perspektivy)// Gorniy jurnal/-1991, № 10, S. 55-59.

https://doi.org/10.31713/m1114

\title{
RESOURCE-SAVING CONTROL SYSTEMS FOR ELECTRIC DRIVES OF MODERNIZED DRILL RIGS FOR OPEN-MINES OF UKRAINE
}

\author{
Khilov V.S. \\ Dnipro University of Technology. \\ Doctor of Technical Sciences, Professor, Ukraine
}

\begin{abstract}
A comparative analysis of the characteristics of DRGs used in opencast mining in Ukraine is given. Experimental studies of the influence of drive systems and drill rigs on the dynamics of the drill process were carried out in the mining and geological conditions of the Central Mining and Processing Plant (Kryvyi Rih, Ukraine). Frequency characteristics and analysis of dynamic properties of automated drive systems and frequency characteristics of transmissions of the rotation
\end{abstract}


mechanism are obtained. The behavior of natural frequency oscillations in closed control circuits of rotary actuators was studied and it was found that they cross the cutoff frequency and fall into the bandwidth from the attenuation band in frequencycontrolled asynchronous motors of new generation drill rigs when using the maximum number of connected tubes in the drill rod. It is established that the lowest oscillation frequencies due to the lateral frequencies generated by the oscillations of the drill rod fall into the fastest internal current loop.

The purpose and objectives of research is energy and resource saving in the process of drill subsoil wells by concentrating the flow of mechanical power in the bottom hole zone and ensuring minimum dynamic loads in the drill machine in the presence of elastic connections and variable natural frequencies in multi mass transmission with concentrated and distributed parameters.

The object of the study is the frequency compatibility of electromechanical processes in the electric drive rotation of the drill rig with distributed parameters taking into account the change of attached distributed and concentrated masses to the transmission.

The subject of research is the elastic properties of transmissions, frequency characteristics of control systems and their mutual influence on the quality of work in electric drives.

\section{Introduction}

In the general technology of open pit mining in the open-cast mines of the Krivoy Rog basin of Ukraine, the cost of drill and blasting operations is about $16-36 \%$ of the total costs of breaking hard rocks. In connection with the rise in the cost of energy carriers, electricity and consumables, the problem of using energy-saving technologies in the extraction of rocks becomes more and more urgent. Today, drill rigs (DRG) are operating in the open-cast mines of Ukraine, which have completely exhausted their standard resource. This state of the DRGs necessitates not only the modernization of existing ones, but also the introduction of a new generation of DRGs with longer DRDs and a multi-mass mechanical system of loweringlifting operations.

Efficiency drill blast holes using roller-cone method is directly determined by the perfection level of electric drive systems. Introduction fast-action transistor AC drive into rotation mechanism composition existing rigs, and also into the rotation and movement mechanisms in the rigs of the new generation instead of thyristor DC drive with middle-action is characterized by increased vibratory loads onto all mechanical designs of the rigs. These loads lead to the release of an energy flow not only in the bottomhole zone, where 
rocks are destroyed, but also in structural elements directly on the machine, which increases mechanical stresses, fatigue of the machine material and leads to emergency failures of the rig (usually of drill mast). The frequency characteristics of the drive systems must be compatible with the dynamic characteristics of multi-mass mechanisms with distributed and lumped masses with changing attached masses, which will ensure the release of the flow of mechanical power within the bottomhole zone and energy and resource saving when drill blast wells. Therefore, the solution of scientific and applied problems to establish the regularities of the influence to dynamic of electromechanical and hydromechanical parameters of DRGs as well as further development on this basis of the theory of high-speed automated electrical installations are now gaining relevance.

\section{The problem formulation}

Blast hole drill is one of the most energy-intensive and materialintensive processes in the existing technology for the extraction of iron ore raw materials on open-pit mining works in Ukraine. Increasing the efficiency of rock destruction with a roller cone bit, is connected which the level of perfection of the DRGs drive systems. The works (Quang 2010, Novotny 1996, Boldea 1992, Boldea 2006) and many others are devoted to the development of the modern electromechanical systems operation theory.

The purpose of this study is energy and resource saving in the drill blast holes' process by concentrating the flow of mechanical power in the bottomhole zone and also obtaining minimum dynamic loads in the DRG in the presence of elastic mechanical links and changing natural vibration frequencies of a multimass transmission with lumped and distributed parameters.

Achieving this purpose involves solving the following tasks:

- to develop a method for controlling the drill process with the formation of the mechanical characteristics with the variable stiffness on the roller cone bit, depending on the hardness of the rock which drill, through the influence on the motor rotation speed and DRD in bottom zone;

- to evaluate the effect of forced and natural oscillations of the DRD on the dynamics of the operation of DRG with a thyristor DC drive (DRG SBSh-250MN-32) and thyristor and transistor AC drives 
introduced with the participation of the author (DRGs SBSH250MN-32 and SBSHS-250N);

- to fulfill further evolution of the scientific basis of the creation system of electric drive rotation taking into account technological features and had being developed control method of drill;

- to study the electrohydromechanical transmission as an object of automatic control of the electric drive of lowering-lifting operations and to establish regularities in the change in the characteristic vibration frequencie;

- to fulfill further evolution of the scientific basis for constructing the drive of lowering-lifting operations in accordance with object peculiarities and had being developed a method for controlling the drill process;

- to fulfill further evolution of the active sequence correction method using fuzzy control systems for optimal control electric, electromechanical and electro-hydro-mechanical processes.

The object of study is the frequency compatibility of electromechanical processes and electro-hydro-mechanical processes in rotary DRD with distributed parameters and the drive round-trip and displacementing rod with lumped parameters associated with the changes in the distributed and lumped masses in the transmission.

The object of the research is the frequency compatibility of electromechanical and electrohydromechanical processes in the electric drive of rotation of the DRD with distributed parameters and in the electric drive of lowering-lifting operations and feeding rod with lumped parameters, taking into account changes of the added as well as distributed and lumped masses into the transmission.

\section{Materials of research}

3.1. State-of-the-art and development trends of drive systems for rotary cutter blast hole drill

In the open pits of Ukraine mainly in operation are rigs of medium type SBSh-250MN-32 with thyristor DC drives in the rotation mechanisms of the DRD and unregulated asynchronous drives in the mechanisms of lowering-lifting operations and feeding the DRD as well in the mechanisms of DRG movement and in the compressor of the pneumatic transport system. 
Machine-Building Plants of Ukraine have created:

- DRG of type USBShS-250A (developer Krivoy Rog Plant of Mining Machine Builder KZGM, Krivoy Rog, Ukranian, has been in operation at Poltava Ore Mining and Processing Plant since 2004; equipped with drive systems, which are similar to systems of DRG SBSh-250MN-32 type);

- new generation DRGs SBSh-250/ 270-32 (developer NovoKramatorsk Machine Building Plant NKMZ, Kramatorsk, Ukranian; operated at Ingulets Ore Mining and Processing Plant since 1999; equipped with thyristor DC drive in the mechanism of rotation, hydraulic drives in mechanism of movement and lowering-lifting of DRD);

- SBShS-250N (developer NKMZ; operated on the Central Ore Mining and Processing Plant since 2003; equipped with transistor $\mathrm{AC}$ drives in the mechanisms of rotation, rod lowering-lifting and movement of rig, which are introduced according to the recommendations of the author).

Along with the development of a new generation DRGs, the existing ones are being modernize. According to the author's recommendations, when upgrading rigs of type SBSH-250MN-32, have introduced drive $\mathrm{AC}$ system in the mechanisms of DRD rotation, which are operated in the Central Ore Mining and Processing Plant: thyristor drive AC with current source (in operation since 1998); Transistor AC drives with a voltage source (in operation since 2005).

The transistor AC drive systems using instead of DC thyristor drives has significantly changed the work dynamics of DRGs in the process of drill blast holes. To establish the quantitative characteristics of the operation of the DRGs electromechanical systems, experimental studies were carried out directly in the mining and geological conditions of the Central Ore Mining and Processing Plant. Dynamics of the head cross-arm of DRD rotation mechanism rig rod with four drive systems is experimental studed: for SBSh-250MN-32 type machines equipped with thyristor and transistor drives DC and $\mathrm{AC}$, and for SBShS-250N type machine equipped with transistor AC drive.

Oscillograms of transient in the transistor drive of the DRG rotation for SBShS-250N type shown in Fig. 1a (drill of leached oxidized martite-hematite hornfels: the strength factor on the scale of Prof. M.M. Pro- 
todyakonov - from 13 to 15 ; drill category by the scale of the Central Ore Mining and Processing Plant - IV; the rocks are very fractured, the distance between the fractures is from 0.2 to $0.3 \mathrm{~m}$ ).

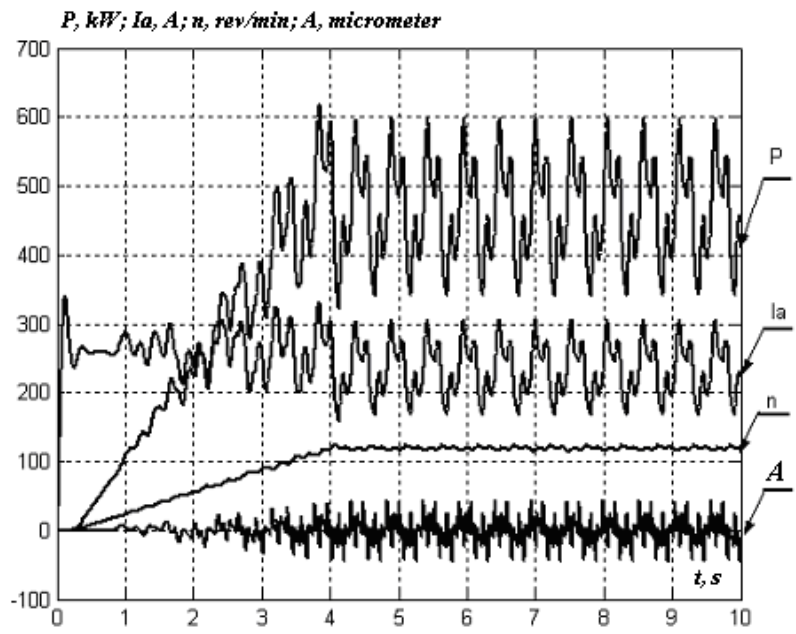

Fig. 1. Oscillograms of transients in the rotation drive of DRG SBSh $-250 \mathrm{MN}-$ 32 with system of frequency converter- induction motor with the inverter voltage: A-vibration displacement of the pressure traverses of the head top (axial pressure on the rod of $250 \mathrm{kN}$, the drill with the three DRDs)

Harmonic analysis (Fig. 2) of the vibrations of the drill head pressure traverse confirmed the well-known position that an increase in the bit rotation frequency leads to an increase in the frequency and amplitude of forced vibrations. Along with the known regularity, a new one appeared: in the spectra of the amplitude-frequency characteristics of the vibrations of the new generation DRG SBShS-250N type, a harmonic appears at a frequency of $f=1.02 \mathrm{~Hz}$, which does not depend on the rotation frequency of the DRD. Other harmonic components are subject to the same law, which was on the existing rigs type SBSh-250MN-32. 

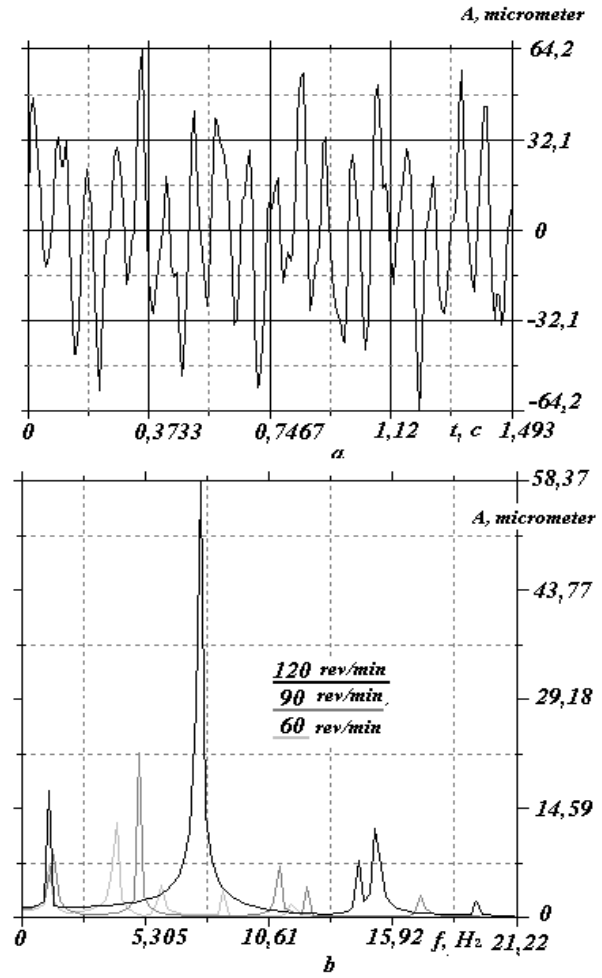

Fig. 2. Oscillogram vibration displacement of head projectile at $60 \mathrm{rev} / \mathrm{min}(a)$ and the amplitude spectrum of vibration frequency characteristics $(b)$ of the machine

SBSh -250MN-32 with transistor AC drive system SIV - induction motor (axial pressure on rod $250 \mathrm{kN}$, drill with three rods)

Other harmonic components obey the same regularity that turned out to be on the existing BS of the SBSh-250MN-32 type. The appearance of the oscillation harmonic, which does not depend on the rotation frequency and is located in the passband of the control system, indicates the need to take into account the effect on the dynamics of the drill process not only of forced oscillations, which are characteristic of the DRG SBSh-250MN-32 type, but also of the natural oscillation frequencies of the stave СБШС - $250 \mathrm{H}$ machine. The use of a transistor frequency-controlled drive on the SBSHS-250N machine led to an increase in high-frequency components in the shaft rotation frequency (DRD) and motor current, Table 1 (where denoted with SIT, VIN - standalone invert- 
er current and voltage).

Along with the general industrial electric drive, which is now implemented at the DRGs, object-oriented drives with automatic control of the modes of drill blast holes for roller cone machines are known, which are based on next control methods: stabilization of the torque, minimum costs for drill a meter of borehole, maximum velocity drill. However, such systems drive the widespread introduction in the Krivoy Rig basin did not find, as ideas have being putted into their foundation at experimental verification are not received confirmation. Therefore, when developing a method for controlling electric drives of feed and rotation of a rod in the process of roller cone drill, we take on based the control method put forward at the IvanoFrankivsk National Technical University of oil and gas and partially experimentally tested at the Poltava Ore Mining and Processing Plant (where mining and geological conditions are similar to those of the open pits of the Kryvyi Rih basin) with control of the power of the engine rotation of the rod, which helps to increase the durability of the bit and reduce the cost of drill and blasting operations.

In order to increase the durability of a roller cone bit by maintaining the power flow in the bottomhole zone, the author has developed a method for controlling the drill process with control of the electric drives of the rotation mechanisms and the lowering-lifting of the DRD, in which hard mechanical characteristics are formed on a roller cone bit when drill in rocks with a strength $f \leq 10-13$ on the scale of prof. M.M. Protodyakonov and soft mechanical characteristics in harder rocks. When drill rocks that are variabled by physical and mechanical properties, the control method provides automatic selection of mechanical characteristics depending on the strength of the rock. The control method is protected by a patent of Ukraine (Khilov V.S. 2003).

Table 1

Quantitative characteristics ripple depending on the type of electric drive systems rotation rod and DRGs

\begin{tabular}{c|c|c}
\hline \multirow{2}{*}{$\begin{array}{c}\text { The rotation drive types } \\
\text { and DRGs types }\end{array}$} & \multicolumn{2}{|c}{ Peak-to peak ripple during drill, \% } \\
\cline { 2 - 3 } & motor speed (rod) & motor current \\
\hline $\begin{array}{c}\text { Thyristor DC drive, } \\
\text { rig SBSh-250MN-32 }\end{array}$ & 0,51 & 28,4 \\
\hline Thyristor DC drive SIT - & 2,56 & 25,3 \\
\hline
\end{tabular}




\begin{tabular}{c|c|c}
\hline $\begin{array}{l}\text { induction motor, } \\
\text { rig SBSh-250MN-32 }\end{array}$ & \\
\hline $\begin{array}{c}\text { Transistor AC drive SIV - } \\
\text { induction motor, } \\
\text { rig SBSh-250MN-32 }\end{array}$ & 3,51 & 25,6 \\
\hline $\begin{array}{c}\text { Transistor AC drive SIV - } \\
\text { induction motor, } \\
\text { rig SBShS-250N }\end{array}$ & 3,02 & 27,1 \\
\hline
\end{tabular}

The implementation of the developed method for controlling the drill process leads to the need to control and limit at permissible levels in electric drives: of rotation of the DRD - the flow of mechanical power on a roller cone bit in the bottomhole zone; of the lowering-lifting DRD - the pressure in the hydraulic system and the linear velosity of movement of the drill, which requires further development of scientific foundations for the creation of object-oriented drive systems for the DRGs of a new generation.

Now the problem of the mutual influence of the dynamic characteristics of high-speed transistor AC drives and the frequency characteristics of the transmission of DRGs is insufficiently studied and is relevant. This is due to the introduction of both DRGs with new design solutions and electric drives of a new generation, which significantly changed the natural oscillation frequencies of the electrogidro-mechahical systems of lowering-lifting operations and feed and electro-mechanical rotation of the DRD.

3.2 Analysis of the DRD dynamic properties as an object of automatic control

In the control system of the rotation electric drive, as shown by experimental studies (Khilov 2004, Pivnyak 2005), it is necessary to take into account the frequency properties of the control object. For this purpose the frequency characteristics of DRDs (Khilov 2020), which are used in the open pits of Ukraine in the roller cone bit rigs, were determined.

The DRGs rods have a length from $8 \mathrm{~m}$ (rigs USBSHS-250A, SBSh-250MN-32) to $11 \mathrm{~m}$ (rig SBShS-250N). From a design point of view, they are hollow rods of circular cross-section, one end of which is pivotally supported on the roller cone bit, and the other one has a sliding pinching in the head cross-arm of DRD. The DRD is under pressure from the feed force. When determining the frequencies of natural vibrations, the DRD was investigated as a linear sys- 
tem with a uniformly distributed mass, in which longitudinal, torsional and transverse vibrations do not depend on each other. The mass of the roller cone bit was neglected in the analytical study.

As a result of theoretical studies, a mathematical model was obtained for determining the natural frequencies of longitudinal, torsional and transverse vibrations both for a DRD with one rod and during its growth, Table 2 (where $u$ - the longitudinal displacements of the current section of the rod; $t$ - the time; $\varphi$ - the angle of rotation of the cross section rod; $x$ current distance; $y$ - cross-sectional displacement of the rod). On the basis of the model, a method was developed for calculating natural vibrations, which made it possible to calculate the vibration frequencies of a DRD with a variable number of rods (Khilov \& Plakhotnik 2004, Pivnyak 2003, Kozhevnikov \& Khilov 2012).

From a comparison of the natural frequencies of longitudinal, torsional and transverse vibrations, obtained by calculation, with the natural frequencies that were identified in experimental studies (Khilov 2006), it follows that when drill with one or two rods, regardless of the type of DRGs, the natural frequencies of longitudinal and torsional vibrations of the rod do not fall within the passband of both DC and AC drives. When drill with three rods in the SBSH$250 \mathrm{MN}-32$ rig, low-frequency natural transverse oscillations of the rod with a value of $2.36 \mathrm{~Hz}$ were experimentally recorded, their calculated value according to the developed method was $2.48 \mathrm{~Hz}$. When drill with three rods with the SBShS-250N rig, the natural lowfrequency transverse vibrations of the rod with a cyclic frequency of $1.02 \mathrm{~Hz}$ were experimentally recorded. The calculated value of this frequency is $1.05 \mathrm{~Hz}$.

Table 2

DRD natural oscillations calculated equations

\begin{tabular}{c|c|c}
\hline $\begin{array}{c}\text { Longitudinal } \\
\text { oscillations }\end{array}$ & Torsional vibrations & Transverse vibrations \\
\hline$\frac{\partial^{2} u}{\partial t^{2}}=C_{1}^{2} \frac{\partial^{2} u}{\partial x^{2}}$ & $\frac{\partial^{2} \varphi}{\partial t^{2}}=C_{2}^{2} \frac{\partial^{2} \varphi}{\partial x^{2}}$ & $E \cdot J \cdot \frac{\partial^{4} y}{\partial x^{4}}+R \cdot \frac{\partial^{2} y}{\partial x^{2}}+m \cdot \frac{\partial^{2} y}{\partial t^{2}}=0$, \\
& $y=X_{y}(x) \cdot T(t)$. \\
\hline
\end{tabular}




\begin{tabular}{|c|c|c|}
\hline $\begin{array}{c}\text { Longitudinal } \\
\text { oscillations }\end{array}$ & Torsional vibrations & Transverse vibrations \\
\hline $\begin{array}{c}C_{1}=\sqrt{E / \rho} \\
E \text { - elastic mod- } \\
\text { ulus; } \\
\rho \text { - density }\end{array}$ & $\begin{array}{c}C_{2}^{2}=G / \rho \\
G \text { - shear modulus }\end{array}$ & $\begin{array}{c}m-\text { DRD distributed mass intensity } \\
E \cdot J-\text { DRD flexural rigidity; } J- \\
\text { inertia axial moment; } R \text { - displace- } \\
\text { ment force }\end{array}$ \\
\hline $\begin{array}{l}X_{u}=C_{u} \sin \frac{p_{u}}{C_{1}} x+ \\
+D_{u} \cos \frac{p_{u}}{C_{1}} x\end{array}$ & $\begin{array}{l}X_{\varphi}=C_{\varphi} \sin \frac{p_{\varphi}}{C_{2}} x+ \\
+D_{\varphi} \cos \frac{p_{\varphi}}{C_{2}} x\end{array}$ & $\begin{array}{l}\text { Equation solution } \\
\frac{\ddot{T}}{T}=-p^{2} ; \frac{E \cdot J}{m} \cdot\left(X_{y}^{I Y}+\alpha^{2} X_{y}^{I I}\right)=p^{2} \\
X_{y}=C_{1} \cdot \operatorname{sh}\left(S_{1} \cdot x\right)+C_{2} \cdot \operatorname{ch}\left(S_{1} \cdot x\right)+ \\
+C_{3} \cdot \sin \left(S_{2} \cdot x\right)+C_{4} \cdot \cos \left(S_{2} \cdot x\right)\end{array}$ \\
\hline $\begin{array}{l}p_{u} \text { - longitudi- } \\
\text { nal oscillations } \\
\text { natural frequen- } \\
\text { cy; } \quad l-\text { DRD } \\
\text { length }\end{array}$ & $\begin{array}{l}p_{\varphi}-\text { torsional nat- } \\
\text { ural frequency }\end{array}$ & $\begin{array}{c}p-\text { transverse oscillations natural } \\
\text { frequency }\end{array}$ \\
\hline$X_{u}^{\prime}=0$ & $X_{\varphi}^{\prime}=0$ & $\begin{array}{c}\text { Border conditions }(x=0) X_{\mathrm{y}}=0, \\
X_{\mathrm{y}}^{\prime}=0\end{array}$ \\
\hline$X_{u}^{\prime}=0$ & $X_{\varphi}^{\prime}=0$ & $\begin{array}{c}\text { Border conditions }(x=l) X_{\mathrm{y}}=0, \\
X_{\mathrm{y}}^{\prime}=0\end{array}$ \\
\hline $\cos \left(\frac{\mathrm{p}_{\mathrm{u}}}{\mathrm{C}_{1}} \cdot l\right)=0$ & $\sin \left(\frac{p_{\varphi}}{C_{2}} \cdot l\right)=0$ & $\begin{array}{l}\begin{array}{l}\text { Equations for Determining Natu- } \\
\text { ral Frequencies }\end{array} \\
X_{y}=C_{1} \cdot \operatorname{sh}\left(S_{1} \cdot x\right)+C_{2} \cdot \operatorname{ch}\left(S_{1} \cdot x\right)+ \\
+C_{3} \cdot \sin \left(S_{2} \cdot x\right)+C_{4} \cdot \cos \left(S_{2} \cdot x\right)\end{array}$ \\
\hline
\end{tabular}

The low-frequency components of the transverse vibrations of the DRD do not directly affect the dynamic processes in the drive system. However, they lead to unacceptable dynamic loads not only on the DRD, but also on the DRG as a whole, which significantly reduces the average time between failures of structural units and significantly limits the productivity of drill and blasting operations, therefore the drive system must limit transverse vibrations of the DRD to an acceptable level.

The dynamics of the AC drive system is directly affected by torsional vibrations of the $\mathrm{DRD}$, provided that its natural frequencies fall within the passband of the current loop as well as speed one. 
These conditions are fulfilled in the AC drive system introduced on the СБШС-250H rig with a transistor autonomous voltage inverter with pulse-width modulation (SIV-PWM) with a speed loop passband of $200 \mathrm{rad} / \mathrm{s}$, when drill with four rods.

Operation of a DC drive system with a thyristor voltage converter and a speed loop passband of no more than $50 \mathrm{rad} / \mathrm{s}$ in SBSHS-250N and SBSh-250MN-32 DRGs does not lead to the fall into passband of the natural frequencies of the DRD torsional vibrations.

\subsection{Drive system for rotation of the DRD}

To obtain the desired hyperbolic dependences between the rotation frequency of the rod and the strength of the rock, which is destroyed by the bit according to the developed drill method, it is necessary not only to maintain the rotation speed of the electric motor (bit) at a constant level when drill soft rocks, but maintain also the flow of power on the roller cone bit at a constant level when the destruction of hard rocks in the area of the work face. In this case, the control system should automatically, without operator intervention, select the rotation speed of the roller cone bit at a variable and a priori unknown value of the strength of the rock being drilled.

When drill with one or two rods (Section 3.2), the lowest frequency of torsional vibrations of DRD of the SBShS-250N, USBShS-250A and SBSH-250MN-32 type rigs is higher than the cutoff frequency of the stator current and the rotation speed control loops (Khilov V.S. 2006). Therefore, under such conditions, when developing an electric drive system for the rotation of the DRD with control of the electromagnetic power, it is possible to ignore the influence of the natural torsional oscillations of the DRD on the control dynamics, since they are in the attenuation band outside the passband of the control system.

It has been established (Khilov V.S. 2011) that the direct connection of the external loop of electromagnetic power leads to the parallel connection of the control loops of the rotation frequency and current through the presence of cross-links in the control object. For such a control system, a method has been developed for calculating the dynamic correction of the power control loop (Khilov V.S. 2012), which takes into account the perturbation across the motor stator current channel to the power control loop. With the introduction of a permanently switched on external power control loop, the power of the drive system is effectively maintained at a 
given level when drill in hard rocks, and hard mechanical characteristics are realized when drill soft and fractured rocks.

To implement this control method, a power control system using nonlinear correction in feedback (Khilov V.S. 2012) has proposed and investigated. For this purpose, the reference signal at the input of the speed controller is divided into a signal that is proportional to the moment of resistance on the roller cone bit (Fig. 3).

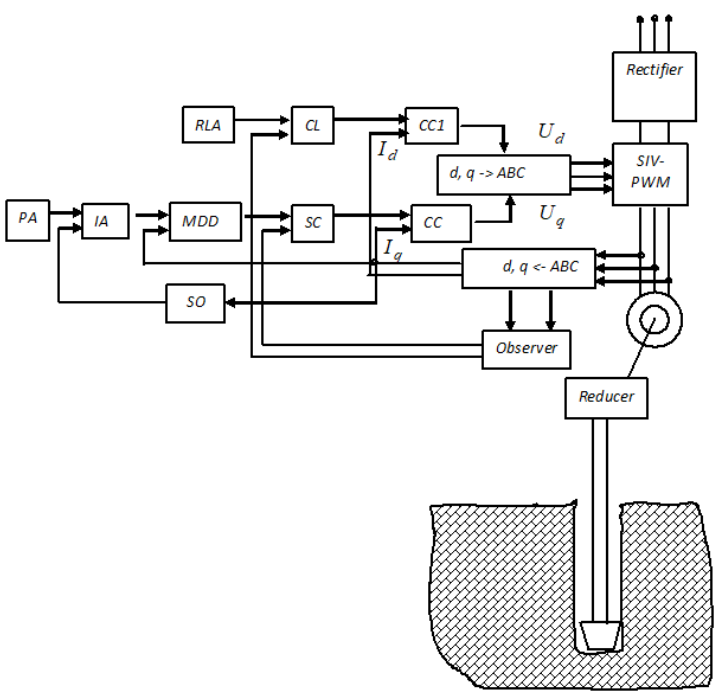

Fig. 3. Vector control system of destroyed rock power with roller cone bits: $P A$, $I A, R L A$ - setting devices of power, intensity and nominal linkage; $S C, C L, C C, C C 1$ - speed controller, linkage and stator currents; $S O$ - vibration sensor; $M D D$ - multiplier-divider unit; $S I V-P W M$ - autonomous voltage inverter with $P W M$

The influence of nonlinear power correction on the stability of the control system is investigated (Khilov V.S. 2013). The characteristic equation of the external control loop is distinguished, which is a polynomial of the third degree. Therefore, the quality of management is assessed using the Visegradskiy diagram (Fig. 4). 


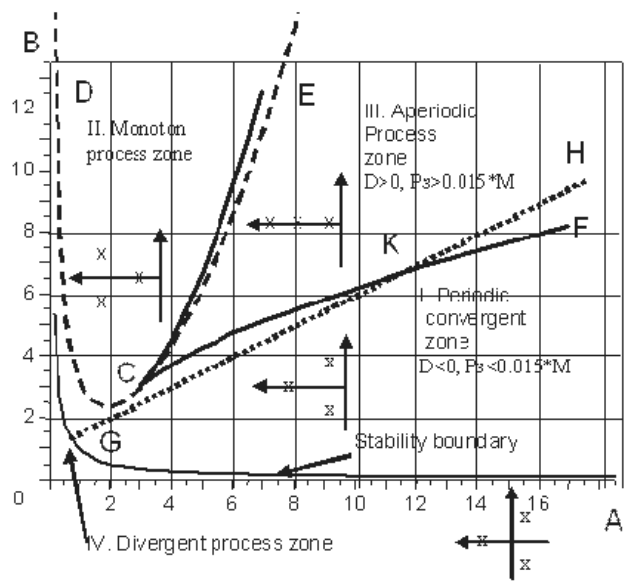

Fig. 4. Zones of quality transient of control system with nonlinear power regulator

The diagram used Vyshnegradsky coefficients $A, B$, which are quantitatively determined by the equations

$$
\begin{gathered}
A=\left(a^{2}{ }_{u} b^{2}{ }_{u} T^{2}{ }_{c} a_{u} b_{u} T_{c} P_{3} T_{M} / M / K_{u}\right) /\left(a_{u}^{2} b_{u} T^{3}{ }_{c}\right)^{2 / 3} ; \\
B=\left(a_{u} b_{u} T_{c} a_{u} b_{u} T_{c} P_{3} T_{M} / M / K_{u}\right) /\left(a^{2}{ }_{u} b_{u} T^{3}{ }_{c}\right)^{1 / 3},
\end{gathered}
$$

where $a_{u}, b_{u}$ - tuning coefficients; $T_{c^{-}}$circuit current time constant; $P_{3}$ - the reference signal; $M$ - motor torque; $T_{M}$ - mechanical constant; $K_{u}$ - transfer coefficient of the speed sensor.

In Fig. 4, the GH line is the locus of points belonging to the vertices of the parabolas at the current values of the task for the power of destruction of the rock and the moment of resistance on the bit. It characterizes the quality of the transition process. With the minimum values of the Vyshnegradskiy coefficients $A_{\min }=\sqrt[3]{a_{u}^{2} \cdot b_{u}}$, $B_{\min }=\sqrt[3]{a_{u} \cdot b_{u}^{2}}$ and the coefficients of the velocity loop tuning $a_{\mathrm{I}}=b_{\mathrm{I}}=1$ line $\mathrm{GH}$ begins on the stability boundary, while $a_{\mathrm{U}}=b_{\mathrm{\amalg I}}=2$ lies in the area of sustainable transient. The quality line of the transient process GH is located in zones I and III, without falling into zone IV. This indicates that the necessary and sufficient condition for maintaining the stability of the control system is not violated even with the introduction of nonlinear correction (Fig. 3).

If there are more than three rods in the DRD (Khilov V.S. \& 
Glukhova N.V. 2019, 2020.), torsional vibrations of the DRD are lowfrequency and fall within the passband of the control system of the drive AC rotation of the SBSHS- $250 \mathrm{~N}$ rig, i.e. they are affected onto the operation of the control system when drill with a completely assembled DRD, which degrade the control quality of the entire electromechanical installation and increase vibration loads on the DRG as a whole.

For the study, only the frequency of the lowest vibrations of the DRD was taken, which fell into the passband, and other frequencies that are in the attenuation band were not taken into account. The equivalent circuit of torsional vibrations is a system with concentrated masses of the rotor of an induction motor and the mass of the DRD reduced to the rotor speed. These two masses connected by elastic element stiffness is determined by the lowest frequency torsional vibrations of DRD. In selected calculation circuit there are additional dynamic links in the control loops (Table 3, where $T_{I}, T_{E M}$, $T_{y}$ - time constants: electromagnetic, electromechanical, torsional vibrations composition; $\Gamma, \gamma$ - coefficients ratio of inertial mass; $\xi_{y^{-}}$ damping coefficient of elastic vibrations DRD).

The dynamic characteristics of control loops under the influence of the elastic properties of the DRD on the control processes in the drive system are analysed.

It was established that when using classical PID controllers, only local optimal tuning of the control system is possible.

When the number of connected DRDs is changed from one to four, the classic PID control settings do not provide optimal dynamic performance over the entire range.

This is possible only with the use of adaptive controllers, which must change not only their parameters, but also the control structure within wide limits, and also provide the ability to find derivatives of the fourth-order error signal in the presence of noise in the control signal.

Therefore, the classical control system can function effectively only if decrease rapidity of 
Table 3

Additional dynamic links in the control loops of the drive rotation

\begin{tabular}{c|c}
\hline Loop & Loop additional dynamic link \\
\hline \multirow{2}{*}{ Current } & $\left(T_{I} \cdot p+1\right) \cdot p \cdot T_{E M} \cdot \gamma \cdot$ \\
\cline { 2 - 2 } & $\left(p^{2} \cdot T_{y}^{2}+p \cdot 2 \cdot \xi_{y} \cdot T_{y}+1\right)$ \\
\hline $\begin{array}{c}\text { Rotation } \\
\text { frequency } \\
\text { of motor }\end{array}$ & $+p^{2} \cdot \gamma \cdot T_{y}^{2}+p \cdot 2 \cdot \xi_{y} \cdot T_{y}+1$ \\
\hline $\begin{array}{c}\text { Linear } \\
\text { speed of } \\
\text { DRD }\end{array}$ & $\frac{p^{2} \cdot \gamma \cdot T_{y}^{2}+p \cdot 2 \cdot \xi_{y} \cdot T_{y}+1}{p^{2} \cdot T_{y}^{2}+p \cdot 2 \cdot \xi_{y} \cdot T_{y}+1}$ \\
\hline
\end{tabular}

action to a level where its own characteristic frequencies are shifted to the zone of damping control loops. In the field of classical control systems is only possible construction of control systems with a low rapidity of action, which is contrary to the quality requirements of the electromechanical system of DRD rotation.

The studies carried out allow us to formulate a concept for the construction of automated drives for DRD rotation of rigs for open pits, according to which, in order to save energy and resources, depending on the strength of the rock, the mechanical characteristic on the roller bit is supported with constant or variable stiffness and limitation of longitudinal vibrations of the DRD by the control system. The concept uses the principles of regulation, in which longitudinal vibrations are limited by influencing the setting signal of the speed setting unit with the simultaneous control and limitation of technological parameters, which leads to the concentration of the flow of mechanical power in the bottomhole zone.

3.4 The electro-hydro-mechanical transmission properties research as object of DRD lowering-lifting drive system control

The DRG SBSHS-250N type by Closed Joint-Stock Company NKMZ that had been designed, significantly differs from SBSh-250MN- 
32 type rig by electro-hydro-mechanical transmission in the mechanism of lowering-lifting of DRD. Into a kinematic link between the drive motor and the drill rog in SBSHS-250N type rig in rod translation displacement are included a hydraulic pump, hydraulic motor (HM) with reducer gear and rope-polyspast system (RTS) (Khilov 2012, Pivnyak 2005).

A mathematical model of the control object have obtained based on decomposition approach in the assumption that the motor and gear having lumped parameters; mass of oil which circulates in the hydraulic system (HS) is not considered in account of its small amount in comparison with other masses; change in viscosity with temperature is neglected, i.e., isothermal processes is considered; oil leakage from the HS is directly proportional to the pressure in the pipes; changing in the volume of lubricating oil in the pipeline directly proportional to the volume of supply pipeline and inversely proportional to the bulk modulus of the pipeline material.

Block diagram of the control object of electro-drive lowering-lifting operation is shown in Fig. 5, where $x_{1}$ - speed $\omega 1$ of the drive motor; $x_{2}$ the moment of $M_{2}$, that is developing by the $H S ; x_{3}$ - speed $\omega_{2} H M ; x_{4}-M_{y}$ moment that corresponds to the force that is transmitted by rope; $x_{5}$ - linear velocity of the DRD, which is reduced to a rotation speed $\omega_{3} ; J_{1}, J_{2}, J_{3}$ moment of inertia of the motor, HM, DRD; $K_{2}$ - hydraulic transmission coefficient; $T_{2}$ - time constant of the HS; $\delta$ - coefficient of leakage in the HS; $c, b$ - coefficients of stiffness and dissipative forces RTS; $M, M_{C}$ torque and resistance moment.

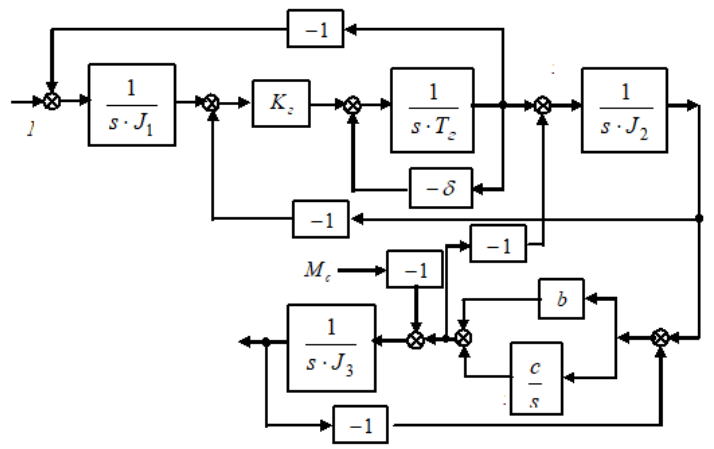

Fig. 5. Block diagram of the control object of the drive lowering-lifting operations and feed DRD 
From the analysis of the obtained mathematical model of the control object of the electric drive of the lowering-lifting and feed operations, it follows that in order to implement the developed method of controlling the drill process, it is necessary to control, in addition to the traditional coordinates (the current and motor speed), also technological coordinates it are the pressure in the hydraulic system, the rotation frequency of the hydraulic motor and linear the velocity of movement of the DRD, which needs a corresponding introduction of the control loops.

The presence of elastic links in the transmission leads to appearance of additional fractional-rational function, the zeros and poles of which are moved from the low to the high frequency region and cross the cutoff frequency of the loop with a decrease in the number of rods in drill string from four to zero.

\subsection{Constructing a system of motor control lowering-lifting and feed $D R D$}

According to the developed method for controlling the drill process, electro-hydro-mechanical drive control system with distributed correction along the loops of dynamic parameters is proposed and investigated (Pivnyak G.G. 2005). The system, in addition to the electro-mechanical parameters of the drive motor, controls the technological parameters defined in Section 3.4 (Khilov 2012), which make it possible to efficiently optimize the dynamic loads in the entire transmission, automate the processes of lowering-lifting and feeding the bit to the bottom, and implement the proposed method for controlling the drill process.

At the beginning of the movement of the drill string with more than three connected rods, in addition to the traditional aperiodic link, the fractional-rational fraction function of the sixth order also enters the current circuit. When tuning the loop to the technical optimum, the classical transfer function of the current regulator must have an inverse transfer function of the loop control object, which is a rather complex controller in implementation, since it is necessary to find high-order derivatives (up to the sixth inclusive) of the error signal. In addition, the regulator must have the properties of adaptation or robustness due to changes in the stiffness of the ropepolyspast system and the weight of the drill string. As the rope length 
is decreased, as well as the decrease in the number of DRDs in the drill string, the characteristic vibration frequencies shift towards large values on the complex plane, crossing the cutoff frequency of the loop.

A traditional PI current controller with a classical tuning does not suppress any of the poles of the control object of the loop, and the presence of additional element in the control object through a significant influence of the circulating electromotive force leads to the loss of astaticism in the current loop.

In addition to the closed loop of the stator current regulation of the induction motor, the mechanical link of the electric drive, an additional transfer link enters the control object of the rotation frequency, which takes into account the elastic properties of the transmission. For the electric drive of the lowering-lifting and feeding operations of a SBSHS-250N medium-type rig, the characteristic oscillation frequencies of the additional dynamic link when moving three or less rods lie in the region that is higher than the cutoff frequency of the rotation frequency loop, therefore, they do not affect the dynamic processes in this loop. When moving four DRDs, which are guaranteed by the manufacturer as a standard operating mode of the DRG, the characteristic oscillation frequencies fall into the passband and significantly change the dynamics of the closed rotation speed loop, i.e. when present four or more rods in the drill string, it is necessary to correct not only the influence of dynamic processes in the current loop by introduction of the first additional regulator, but also the rotation frequency by introducing a second additional regulator.

The characteristic frequencies of the numerator and denominator polynomials of additional dynamic elements that have founded (Table 3) made it possible to reveal the regularity in which the characteristic frequencies of the numerators and denominators (zeros and poles) are periodically repeated in adjacent contours. Only one characteristic frequency in the current loop is determined by the parameters of the induction motor itself and does not depend on changes in the transmission parameters. The characteristic frequencies of the current loops, the rotation speed of the electric motor shaft and the pressure are side ones with respect to the frequency $1 / T y$ and are generated by elastic oscillations of the rope-polyspast system with taking into account the hydravlic system influence, and change nonlinearly depending on the number of rods screwed onto the drill string and the ropes length. 
A regularity has been established between the parameters of the control object, in which the dynamic links, due to the presence of compliance in the transmission, will not be negatively denoted on the dynamic loads in the transmission. So for an electric drive of a medium-type rig, the characteristic oscillation frequencies of an additional dynamic link, when three or fewer rods are moved, lie outside the bandpass of the rotation frequency loop, and therefore they do not affect the dynamic processes in this loop.

On the basis of the research carried out, the scientific foundamentals for the construction of automated electric drives for the drill string lowering-lifting and feeding operations for DRGs new generation for Ukranian open-pit mines condition have been developed. According to which, in order to maintain optimal technological parameters, technological parameters are controlled and limited at an acceptable level - the linear velocity of movement of the drill string, the rotation frequency of the hydraulic motor and hydraulic pressure.

To implement the scientific concept of constructing a control system for electric drives of rotation (Section 3.3) and lowering-lifting operations and supply of the rod (Section 3.5) with correction distributed along the loops, we come to the need to solve the problem: to obtain normalized transient in control loops if the control object contains not only transfer functions of the second order, and fractional-rational functions inclusively up to the sixth order with zeros and poles that can move through the cutoff frequency of the loop. The solution was found in the field of control systems with fuzzy laws, which allow maintaining high-quality transient processes when changing the quantitative characteristics of the control object within wide boundaries.

\subsection{Method of active sequence correction using fuzzy control}

Generalized block diagram of the control object complex EM and EHM installations is shown in Fig. 6, where $W_{\text {оки }}(s)$ - transfer function of the control object compensated part; $\Sigma a_{m n} s^{m} / \Sigma b_{m n} s^{m}-$ additional transfer function that has defined by the transmission elastic properties and is represented as a fraction-rational function (Pivnyak G.G \& Khilov V.S. 2004).

To compensate action of the additional transfer function is necessary to each basic classic controller, an additional regulator connect 
or in series with the generalized transfer function having the form $W_{n}^{\prime}(s)=\Sigma b_{m n} s^{m} / \Sigma a_{m n} s^{m}$ or in parallel with the transfer function $W_{n}(s)$ $=1 /\left(s T_{O T} W_{o k n}(s)\right)\left(\sum b_{m n}-a_{m n}\right) s^{m} /\left(\sum a_{m n} s^{m}\right)$, which has the parameters according to the control loops.

With such compensation, we obtain regulators additionally distributed along the contours with the polynomials of the numerator and denominator, which are equal to the sixth degree - in the current loop of the drive of lowering-lifting and feeding operations, and the fourth degree - in the loop of the rotation frequency of the drive motor of the lowering-lifting drive and the current of the drive rotation of the drill string, which creates difficulties when regulators implemented in the classical form.

If the output signals of all other regulators reduce to the output of the inner regulator, then instead of several connected in parallel to each contour regulator come to the single concentration regulator, which the classical regulators cover in parallel. In this case, get one regulator that has concentrated in the inner-loop controller, and its work algorithm becomes more complex than the work algorithms of the each distributed controllers.

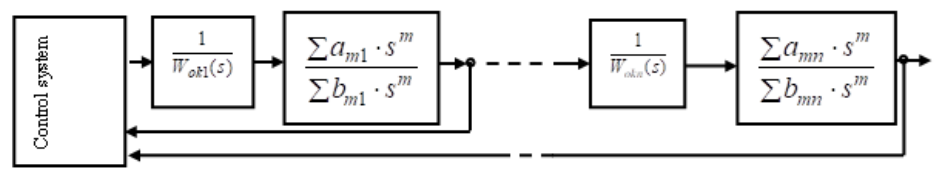

Fig. 6. Generalized block diagram of the control object

We solve the problem of compensating for elastic vibrations in control loops by applying the principles of fuzzy control of complex objects. Instead of classical corrective controllers, we introduce fuzzy controllers into each loop (Fig.7) or bring the action of all additional controllers to the output of the internal classical controller (Fig.8).

In the additional fuzzy corrective controller, there are no a priori assumptions regarding the number and relative position of membership functions, therefore, the synthesis of the fuzzy controller is carried out in two stages. At the first stage, we find the number of membership functions based on the cluster analysis of the input signal vector of the fuzzy controller, and at the second, we adjust the dynamics of its operation on the artificial neural network. 


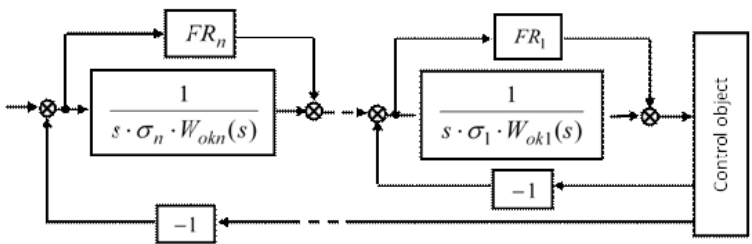

Fig. 7. Control system with additional parallel fuzzy corrective controllers, which are distributed in the loops

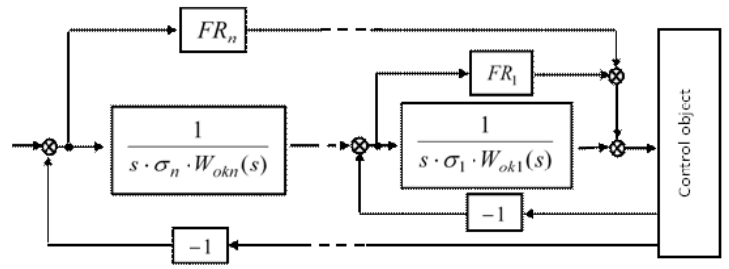

Fig. 8. The control system with additional parallel fuzzy corrective regulators, which concentrated in the inner loop

For a quantitative comparison of the quality of transient processes (Fig. 9), the introduced integral estimates, which take into account the decay rate and the value of the coordinate deviation in aggregate.

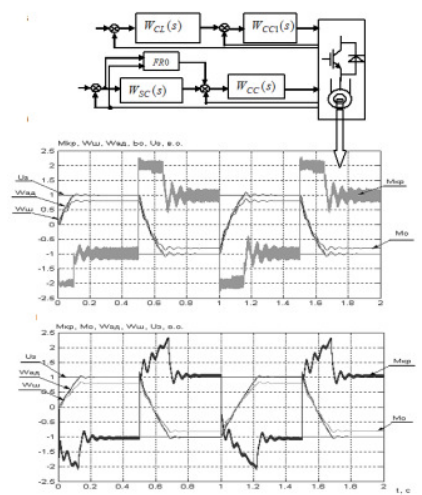

Fig. 9. Vector control system of the rotation drive with hysteresis current regulator, PID speed controller $W_{S C}(s)$, flux linkage $W_{C L}(s)$, current $W_{C C 1}(s)$, PD-fuzzy correction FR0 (a); transients in the system $(a)$ without the fuzzy correction $(b)$, and fuzzy correction (c) where $M_{K P}$ - drive torque, which is turned by phase in angle in $\pi$ radians, $M_{0}$ - reactive resistance moment at roller cone bits, $W_{a d}$ - frequency shaft rotation of $\mathrm{AD}, W_{u}$ - speed of roller cone bit, $U_{3}$ - reference signal to an external speed loop (all variables are given according to their rated values and in relative units are expressed) 
The deviation was calculated not only from the given level, but also the deviation of the motor current and the deviation of the rotation speed to the second and third derivatives, respectively (Yager \& Filev 1984, Zadeh 1976, Pivnyak 2004, Khilov 2011, Khilov \& Glukhova 2004, Terekhov 2001, Terekhov 1996, Leonenkov 2003, Medvedev V.S. 2002).

These estimates $I_{u}, I_{c}$ characterize the approach of transient to extremals, due to the solution of the differential equations of the characteristic polynomials of the optimized circuits of the rotation frequency and motor current. As follows from the analysis of the values $I_{u}, I_{c}$ of the integral estimates of the indicators of the transient process, the greatest deviation from the optimally tuned control system is observed when using a PI-fuzzy controller, and least of all - a PD-fuzzy controller. The PID controller has intermediate indicators of control quality. Therefore, in the algorithms for the operation of a fuzzy current and speed controller, it is enough to limit ourselves to two components - proportional and differential (Pivnyak G.G \& Khilov V.S. 2004).

The use of classical systems with the correction distributed over the loops makes it possible to effectively limit the current and limit values of the coordinates that are controlled, and the use of fuzzy laws effectively compensates for the actions of the elastic properties of the transmission in the control loops. Thus, we obtain the adaptation of control systems for electric drives of rotation, lowering-lifting and feed operations to the operating modes of the DRG and parameters of the control object, which allows the proposed energy and resource-saving control method to be applied in the process of drill blast holes.

Such approach to the action suppression of additional fractionrational functions of high order in the control loops allows implementing the proposed concept of object-oriented automated electric drives of rotation and lowering-lifting DRD of career DRGs of the new generation. In which to improve the quality of regulation the DRD natural torsional vibrations and elastic vibrations in hydro and rope-polyspast systems are suppressed by introducing into laws of the loops classical regulators additional fuzzy control laws.

\section{Conclusions}

As a result of the research, the following results were obtained. 
1. Analysis of dynamic properties of automated driving systems and frequency characteristics of transmission mechanisms of rotation, lowering-lifting and feed DRD of DRGs allowed to put forward the idea of building automatic control system, which concentrates the flow of mechanical power in the area of the bottomhole by suppressing forced transverse vibrations of rotating and natural torsional oscillations, which minimizes the dynamic load on the nodes of DRGs and provides energy and resource efficiency when drill blast holes.

2. The analysis of the methods of automatic control of the process of rotating drill of blast wells at the modern level of technological advances has shown that it is rational to carry out drill on the basis of the energy criterion, according to which the bit has the greatest durability at a uniform energy load, i.e. when supporting the linear growth of the mechanical energy of rock destruction or by keeping the mechanical power at a constant level, which is released in the bitbottom hole contact zone. In this case, depending on the strength of the rock, it is necessary to form a mechanical characteristic on a bit with variable or constant stiffness.

3. It has been established that the most important for the development of the theory of automated drives of rotation of the drill string are such revealed patterns of drill of blast holes:

- in drill modes with a fully assembled string of $33 \mathrm{~m}$ long, transverse natural low-frequency vibrations with a cyclic frequency of $1.05 \mathrm{~Hz}$ are generated in the SBSHS-250N rigs (for the СБШ$250 \mathrm{MH}-32 \mathrm{rig}-2.48 \mathrm{~Hz}$ with a string length of $24 \mathrm{~m}$ ), which do not directly affect on the dynamics of the drive system, but lead to the appearance of additional loads on the units of DRGs, the suppression of which is possible only by reducing the frequency of the rotation of the string, which leads to a decrease in the productivity of mining operations;

- when drill with the string with three or more rods, the angular frequencies of natural torsional vibrations in the SBSHS-250N rig are less than $1861 / \mathrm{s}$ and fall into the passband of the transistor AC drive system with a cutoff frequency of the external loop of 2001 / s, which significantly worsens the quality indicators control of the electromechanical system. It is advisable to compensate for such fluctuations by means of the control of the drive system; 
- low-frequency torsional oscillations of the drill string contribute to the emergence of additional fractional-rational functions of a high order both in the loop of the frequency rotation and in the loop of the current of the rotation electric drive, which, when using classical PID-Controllers, leads to the need to reduce the speed of the entire control system;

- the zeros and poles of additional transmitting functions in the control loops, which are caused by elastic vibrations in the DRD, are repeated in adjacent control loops and, when the added masses in the drill string, shift relative to the loop cutoff frequency.

4. On the basis of the established regularities during drill of blasting wells, the scientific foundations for the construction of automated electric drives for rotation of the drill were further developed, according to which the proposed and studied object-oriented drive systems for rotation of the DRG with a power flow regulator in the zone of rock destruction with nonlinear correction in the feedback channel were proposed and investigated. These systems implement a method for controlling the drill process based on an energy criterion, which provides for the formation of hard mechanical characteristics of an electric drive when drill rocks with a strength factor less than10-13 points on the scale of M.M. Protodyakonov and a transition to soft mechanical characteristics when drill in harder rocks, which will ensure resource saving of roller cone bits.

5. It was found that for the development of the theory of automated electric drives for lowering-lifting and feed DRD to the face, the following revealed regularities are most important:

- to implement an energy and resource-saving drill method, it is necessary to control, in addition to the shaft rotation frequency and motor current, also the pressure in the hydraulic system, the rotation frequency of the hydraulic motor shaft and the linear velocity of the drill string;

- from the elastic properties of hydraulic and rope-polyspast systems in the loops of control objects the oscillations appear, which quantitatively defined by the additional fraction-rational function of the sixth order in the current loop and the fourth - in the loop of frequency rotation;

- in additional dynamic links of adjacent contours, repeating zeros and poles appear, which are excited by elastic vibrations in hydroand rope-polispast systems. Repeated zeros and poles are shifted rel- 
ative to the cutoff frequency of the control loop when changing the added masses in the drill drill string.

6 . On the basis of the analysis of the regularities in rotation systems, lowering-lifting and feeding systems of drill string on bottom delivery, the scientific concept of constructing automated electric drives for DRGs was further developed, according to which, in order to energy and resources save, depending on the strength of the rock that is being drilled, on the roller cone bit is formed mechanical characteristic with constant or variable stiffness and limitation of lateral and torsional vibrations of the drill string, as well as vibrations in hydraulic and rope-polyspast systems. This concept differs in that the forced transverse vibrations of the drill string are limited by influencing on the signal of setting of the rotation speed of the rotation mechanism, and natural torsional vibrations and elastic vibrations in hydro- and rope-polispast systems - by introducing additional fuzzy laws into the control laws of classical loop regulators control with simultaneous control and limitation at the permissible level of technological parameters: in the rotation drive - mechanical power flow in the area of the work face; in the drive of lowering-lifting and feed operations of drill string to the bottom - the linear velocity of movement of the drill, the frequency of rotation of the hydraulic motor and the pressure in the hydraulic system.

7. Within the developed scientific concept of building automated electric drives:

- the behavior of the characteristic frequencies of closed control loops was investigated and it was found that they cross the cutoff frequency and fall into the pass band from the attenuation band of frequency-controlled asynchronous motors in new generation SBSHS-250N rig both in the rotation drive - in the current and rotation frequency loops, and in the drive of lowering-lifting and feed of the rod - in the current loop when the maximum number of connected rods in the drill string. It has been established that the lowest lowfrequency oscillations, which are due to lateral frequencies generated by oscillations of the drill string, hydro - and rope-polistpast systems, fall into the fastest-acting internal current loop;

- for effective suppression of elastic vibrations in the control loops both in the rotation drive and in the drive of lowering-lifting and feed of the bit to the rock face, the established need for the use of 
additional fuzzy controllers distributed along the loops or concentrated in the inner loops. It is proved that fuzzy controllers, which are concentrated or distributed outside the loops, should be applied in the loops, in the passbands of which additional fractional-rational functions have fallen, which are due to the elastic properties of the transmission, the characteristic frequencies of which are lower than the cutoff frequency of the contour with the maximum number of connected rods in the drill string;

- a method for calculating the training set for neuro-fuzzy controllers has been developed, which differs in that to find the training set, transfer functions are used in the form of high-order fractional rational functions, which are due to the properties of the control object.

\section{References}

1. Quang N. P., Dittrich J.-A. 2010. Vector Control of Three-Phase AC Machines: System Development in the practice (Power Systems). Springer, 340. New York.

2. Novotny D. V., Lipo T.A. 1996. Vector Control and Dynamics of AC Drives. Oxford science publications, 450. New York.

3. Boldea I., Nasar S.A. 1992. Vector Control of AC Drives (Handcover). CRC Press Taylor \& Francis Group, 240. New York.

4. Boldea I., S.A. Nasar S.A. 2006. Electric Drives. CRC Press Taylor \& Francis Group, 522. New York.

5. Khilov V.S., Beshta AS, Zaika V.T. 2004. Experience in the Use of Drilling Rigs with a Variable Frequency Drive in the Quarries of Ukraine. 285-289. Mountain information-analytical bulletin. Moscow State Mining University. \#10. (In Russian).

6. Khilov V.S. 2003. The Method of Controlling the Drilling Process. Patent 61548A, Ukraine, International Classification of Inventions E21B45/00. Bulletin \#11, 2003. (In Ukrainian).

7. Pivnyak G.G., Beshta A.S., Khilov V.S. 2005. AC Drive System for Actuator's Power Control. P.368-370. XIII International Symposium on Theoretical Electrical Engineering ISTET'05, Lviv.

8. Khilov V.S., Plakhotnik V.V. 2004. Evaluation of Natural Frequencies of the Drill Rod in Unsteady Modes. 145-150. Collection of scientific works. National Mining University. - 2004. - \# 19. (In Russian).

9. Pivnyak G.G., Beshta A.S., Khilov V.S.2003. Principles of Construction of the Control System of the Electric Drive of Rotation of the Rod String of the Cone Drilling Rig. 141-143. Bulletin of the National Technical University "Kharkiv Polytechnic Institute". Scientific works of National Technical University "Kharkiv Polytechnic".\# 10. V.1. (In Ukrainian).

10. Khilov V.S. 2006. Changing the Dynamics of the Drill Rotator Drive when Using the AC Drive System. 180-184. Bulletin of the Krivoy Rog Technical University. Development of ore deposits. Krivoy Rog. \# 1 (90). (In Russian). 
11. Pivnyak G.G., Beshta A.S., Khilov V.S. 2005. Drive System of Lowering Lifting Operations of the Drilling Rig. 223-225. Bulletin of the National Technical University "Kharkiv Polytechnic Institute". Scientific works of KhPI "Kharkiv: NTU" KhPI ".\# 45. (In Ukrainian).

12. Khilov V.S. 2006. Application of Computer-Aided Drives in New Generation Boring Rigs for Open Pit's in Ukraine. 72-76. Scientific herald National Mining University, \#5.

13. Pivnyak G.G., Beshta A.S., Khilov V.S. 2004. Adaptive Fuzzy Power Regulator to Control the Drilling Process. 47-52. Technical electrodynamics. - Kyiv, \# 6. (In Ukrainian).

14. Khilov V.S. 2011. Drill Spinner Drive Dynamic Performances Correction of Blast Hole Boring Rig. 90-95. The materials of the international conference of “Miners Forum 2012” Dnipropetrovsk, National Mining University.

15. Khilov V.S. 2012. Information and Analytical Characteristics of Drilling Rig Parameters. 90-95. Proceedings of the international conference "Miners' Forum 2012" Dnepropetrovsk, NGU. (In Russian).

16. Terekhov V.M. 2001. Fuzzy Controller Algorithms in Electrical Systems. 55-63. Electricity, \#12. (In Russian).

17. Terekhov V.M., Baryshnikov A.S. 1996. Stabilization of Slow Moving Vehicles Based on Fuzzy Logic. 61-64. Electricity, \# 8. (In Russian).

18. Zadech L.A. 1974. The Concept of a Linguistic Variable and its Application to Approximate Reasoning. 165. SpringerLink.

19. Yager R., Filev D. 1984. Essentials of Fuzzy Modelling and Control. 387. USA: John Wiley \& Sons.

20. Leonenkov A.V. 2003. Fuzzy Modeling in the Environment MATLAB and fuzzyTECH. 736. SPb.: BHV-Petersburg. (In Russian).

21. Medvedev V.S., Potemkin V.G. 2002. Neural network MATLAB 6. 496. Moscow: DIALOG-MEPHI. (In Russian).

22. Khilov V.S. 2013. A Solution to the Problem of Frequency Compatibility Between Drive System and Dynamic Parameters of Drill Rings. 93-103. Energy Efficiency Impotent of Geotechnical Systems. CRC Press.

23. Khilov V.S. 2012. Research of Dynamic-Informational Characteristics of the External Circuit of the Drive of the Drilling rig Movement. 92-97. Scientific Bulletin of the National Mining University. \#2. (In Ukrainian).

24. Khilov V.S. 2012. Research of Information-Analytical Properties of Electromechanical System at Nonlinear Correction by Power Task. 114-120. Scientific Bulletin of the National Mining University. \# 4. (In Ukrainian).

25. Kozhevnikov A.A., Khilov V.S., Belchitskiy A.P., Borisevich. 2012. Experimental Research Pulse Rotary Drilling Technology Tool. 96-108. Scientific Bulletin of the National Mining University. \# 6. (In Russian).

26. Khilov V.S., Glukhova N.V. 2019. Drive Systems of the Drill Machines for Open-Pits in Ukraine: the Situation State and Improvement Ways. 117-129. XIII International Scientific and Practical Conference "Ukrainian School of Mining" as a step towards a new direction of innovative technologies and intelligent systems in the mining industry, v.123. 
27. Khilov V.S., Triputen, V.M. Effect of The Types of Drive Systems of DRGs on The Rock Breaking Dynamics. 158-169. Seventh International Conference IEEE 2020 on Energy Efficient Systems (ESS) 2020.

28. Glukhova N.V., Khilov V.S. 2020. Integrated Assessment of the State of Sewage Mine Waters Based on Gas-Discharge Radiation Method. 129-144. XIV International Scientific and Practical Conference "Ukrainian School of Mining" as a step towards a new direction of innovative technologies and intelligent systems in the mining industry, v.132

https://doi.org/10.31713/m1115

\title{
IMPROVING THE EFFICIENCY OF THE TECHNOLOGICAL COMPLEX FOR THE DEVELOPMENT OF MARINE GAS AND GAS HYDRATE DEPOSITS
}

\author{
Pedchenko N.M. \\ National University «Yuri Kondratyuk Poltava Polytechnic», \\ $\mathrm{PhD}$ Student, Ukraine
}

\begin{abstract}
Purpose. Substantiation and the development of principled schemas, acceptable to the existing technique, methods of production and transportation of natural gas of the offshore fields of gas or gas hydrates. Improving their efficiency by way maximum reduction of the energy consumed is the result of complex consideration of thermal properties and parameters of interaction of the components system within the deposit what is developing.

Findings. The technology of gas hydrates withdrawing with the productive reservoir without energy consumption for the phase transition is proposed. The question of enrichment directly in situ of rocks what containing gas hydrates is considered. Dissociation of residue of the gas hydrates in the rock must be implemented at the expense low potential energy of sea water. The expediency of a compatible development of gas hydrate and gas fields, by way binding of free gas in gas hydrates at the expense of presence of necessary temperature and pressure conditions at passes it through the thickness of sea, is proved. Expediency combination into one a chain of the proposed technology of the development of the offshore fields of gas and gas hydrate with technology of gas transportation in hydrate form and its storage in terrestrial storages is proved.

Originality. Ability to extract gas hydrates from the productive reservoir without the energy consumption for the dissociation, by creating conditions of its recrystallization as a result compatible actions of flooded streams of sea water in a mixture with an abrasive material and pressure fluctuations, is proved. Ability to extract natural gas from residue of gas hydrates in the pulp at the expense of low energy of seawater and changes of its pressure with depth is proved.
\end{abstract}

